\title{
A comparative life cycle assessment of graphene and activated carbon in a supercapacitor application.
}

Matteo Cossutta ${ }^{a *}$, Viliam Vretenar ${ }^{b-d}$, Teresa A. Centeno ${ }^{c}$, Peter Kotrusz ${ }^{d}$, Jon McKechnie ${ }^{a}$, Stephen J. Pickeringe

*Corresponding author

a Bioprocess, Environmental and Chemical Technologies Research Group, Faculty of Engineering, University of Nottingham, Nottingham NG7 2RD, UK - matteo.cossutta@nottingham.ac.uk* . Jon.mckechnie@nottingham.ac.uk

${ }^{b}$ STU Centre for nanodiagnostics, University Science Park Bratislava Centre, Slovak University of Technology, Vazovova 5, 81243 Bratislava, Slovakia - viliam.vretenar@stuba.sk

c Instituto Nacional del Carbón (INCAR-CSIC), Francisco Pintado Fe 26, 33011 Oviedo (Spain) teresa@incar.csic.es

d Danubia NanoTech s.r.o., Ilkovičova 3, 84104 Bratislava, Slovakia - kotrusz@danubiananotech.com e Composites Research Group, Faculty of Engineering, University of Nottingham, Nottingham NG7 Stephen.Pickering@nottingham.ac.uk 


\begin{abstract}
Graphene shows substantial promise in improving the technical performance of a range of applications. For its development and before its potential mass adoption, it is critical to understand the associated cradle-to-grave life cycle environmental impacts. Previous studies on graphene environmental performance do not include end of life and the potential environmental credits generated by graphene reuse. This study undertakes a cradle-to-grave approach to evaluating graphene applications, considering a case study of supercapacitors manufactured with graphene and activated carbon active materials. The analysis includes active materials commercial-size production, supercapacitors production, supercapacitors use phase in an automotive application, and their end of life in which both devices are recycled. With current material performance and energy mixes, the graphene-based supercapacitor would increase impacts in all environmental categories analysed, ranging from $27 \%$ higher human toxicity to $213 \%$ greater ozone depletion and showing a $48 \%$ increase in GHG emissions. This unfavourable result arises due to the tested graphene material exhibiting inferior specific capacitance to the activated carbon comparator, as well as a more energy-intensive production process. Prospective analysis considers hypothetical performance where both active materials reach their theoretical specific capacitance, and the decarbonisation of electricity generation. The environmental impacts of both the activated carbon and graphene supercapacitors are reduced in these prospective scenarios, with the graphene based supercapacitor becoming the least impacting solution due to its lower active material requirements. The graphene-based device shows 36\% lower GHG emission and overall shows lower impacts ranging from $14 \%$ less mineral, fossil and renewable resource depletion to $43 \%$ less photochemical ozone formation. These results support graphene as a valid candidate material for substituting activated carbon in supercapacitors provided graphene technical performance is improved, production optimised, and recycling developed.
\end{abstract}

\title{
Keywords
}

Life Cycle Assessment (LCA); Graphene; Supercapacitor; Activated Carbon; Energy Storage; 


\section{Introduction}

Graphene is a single layer of carbon atoms arranged hexagonally with an hybridized electronic configuration (Zhu et al., 2010). It offers high thermal conductivity (Balandin et al., 2008), high mechanical properties (Lee et al., 2008), and has potential for a range of energy applications. One specific application of graphene, in the form of nanoplatelets, is as the active electrode material in supercapacitors (SCs), providing high usable surface area, superior electrical conductivity and stability over a wide temperature range (Alwarappan et al., 2009). Given the substantial promise of graphene as a material for supercapacitor applications, it is essential to understand the potential environmental implications and sustainability of its production, use and end of life (EoL).

Life cycle analysis (LCA) is an established technique for evaluating the burden that a technology poses on the environment taking into account all phases of the life cycle of a product. At an early stage of development, LCA plays an important role in assessing potential impacts of new technologies, thereby helping to guide research and innovation activities to achieve environmentally-compatible and sustainable products (Arvidsson et al., 2018). Few LCA studies are available on carbon nanomaterials, and most of these focus on carbon nanotubes production like in Griffiths et al. (2013) or Trompeta et al. (2016) or are focused on a specific application such as electromagnetic shielding for satellites (Pourzahedi et al., 2017). Fewer studies have evaluated graphene, considering a range of graphene production routes, including chemical synthesis (Arvidsson et al., 2014), epitaxial growth (Arvidsson and Molander, 2017), a range of chemical, electrochemical and chemical vapour deposition routes (Cossutta et al., 2017), and a biotechnological production route (Khanam et al., 2017). Only a small number of LCA studies have considered graphene uses, including polymer fillers (Long et al., 2018), transparent electrodes (Arvidsson et al., 2016), corrosion inhibition (Upadhyayula et al., 2017), and conductive plating (Guarino et al., 2017). All these studies show that, where graphene improves the selected function, its use can reduce environmental impacts compared with traditional materials. To date, limited attention has been paid to end of life of graphene-containing products, and no LCA study has considered the recovery and reuse.

The environmental impacts of supercapacitors has been studied from perspectives of electrical mobility (Zimmermann et al., 2015) and renewable energy systems with energy storage (Lekakou et al., 2015). Carbon nanotubes were evaluated as active material in one study (Weil et al., 2012) considering energy consumption. The results identified the high energy intensity of laboratory-scale carbon nanotube production and noted the importance of production scale-up to reduce its environmental impact.

A key limitation of existing nanomaterial LCA studies is the unclear emission of nanoparticles across the life cycle and the effects of those emissions on human bodies and the environment. While nanoparticles hazards are known for both carbon nanotubes (Khalid et al., 2016) and 
graphene (Lalwani et al., 2016), the likelihood of emission and the health risk associated with the exposure to nanomaterials release is not clear. Their size and structure might result in different psychochemical and transport properties if compared to basic materials, and in a different way of interacting with the environment and live organisms. Due to the limited information about their rate of release, intake, uptake and transport properties, a dedicated characterisation factor for nanomaterial toxicity has yet to be formalised. The lack of a dedicated impact category for nanomaterials toxicity has been noted since the first LCAs performed on carbon nanomaterials (Bauer et al., 2008) and their applications (Healy et al., 2008). This issue has been reported in detail in several reviews on LCA of nanomaterials, for example for carbon nanotubes (Upadhyayula et al., 2012) and nanomaterials in general (Gilbertson et al., 2015). Preliminary methods have been proposed like probabilistic models (Sun et al., 2016) and material grouping by similar psychochemical properties (Landvik et al., 2018), but the problem still remains without a solution (Salieri et al., 2018).

To better understand the potential contributions of graphene-based technologies toward sustainability objectives, it is necessary to simulate future manufacturing and product systems that account for the specific performance in a particular application. Graphene is a relatively new material with no defined standards for chemical and physical properties, and so it is fundamental to understand the technical performance of the material in specific applications. Toward this goal, the current study evaluates a case study application of graphene use in supercapacitors and compares it to a state-of-the-art activated carbon-based supercapacitor available on the market. The assessment takes, for the first time, a thoroughly comprehensive approach to evaluating graphene-based products that considers alternative graphene production routes, corresponding material properties, product manufacture, use in an automotive application, and end-of-life recycling, including the recovery of nanomaterials for reuse. Forward-looking scenarios, considering improvements in material characteristics and decarbonisation of electricity inputs, enable evaluation of the impacts of graphene and supercapacitors in future.

\section{Methods}

This study evaluates a supercapacitor application, wherein the advantages of graphene high specific surface area, theoretically up to $2630 \mathrm{~m}^{2} / \mathrm{g}$, and electrical conductivity can be exploited in its use as the active electrode material. Results are compared with a conventional supercapacitor, using activated carbon (AC) as the active electrode material, to quantify the relative performance of these alternative materials across the full life cycle, including material production, product manufacture, use, and recycling at end-of-life. A specific supercapacitor application is evaluated, where the devices are used to power car door mirrors as part of a photovoltaic-powered assembly completely detached from the car main battery. The prototype uses a mirror installed by Fiat Chrysler Automotive (FCA) in one of their vehicles. The findings of the present study can be easily transferred to larger scale supercapacitor 
applications such as regenerative braking, start-stop systems, electric turbochargers and many others.

\subsection{Life cycle assessment methodology}

LCA models developed in this study follow the International reference Life Cycle Data system methodology (ILCD - (JRC, 2010)) and include all suggested impact categories related to climate change, ecosystem quality, human health, and resources.

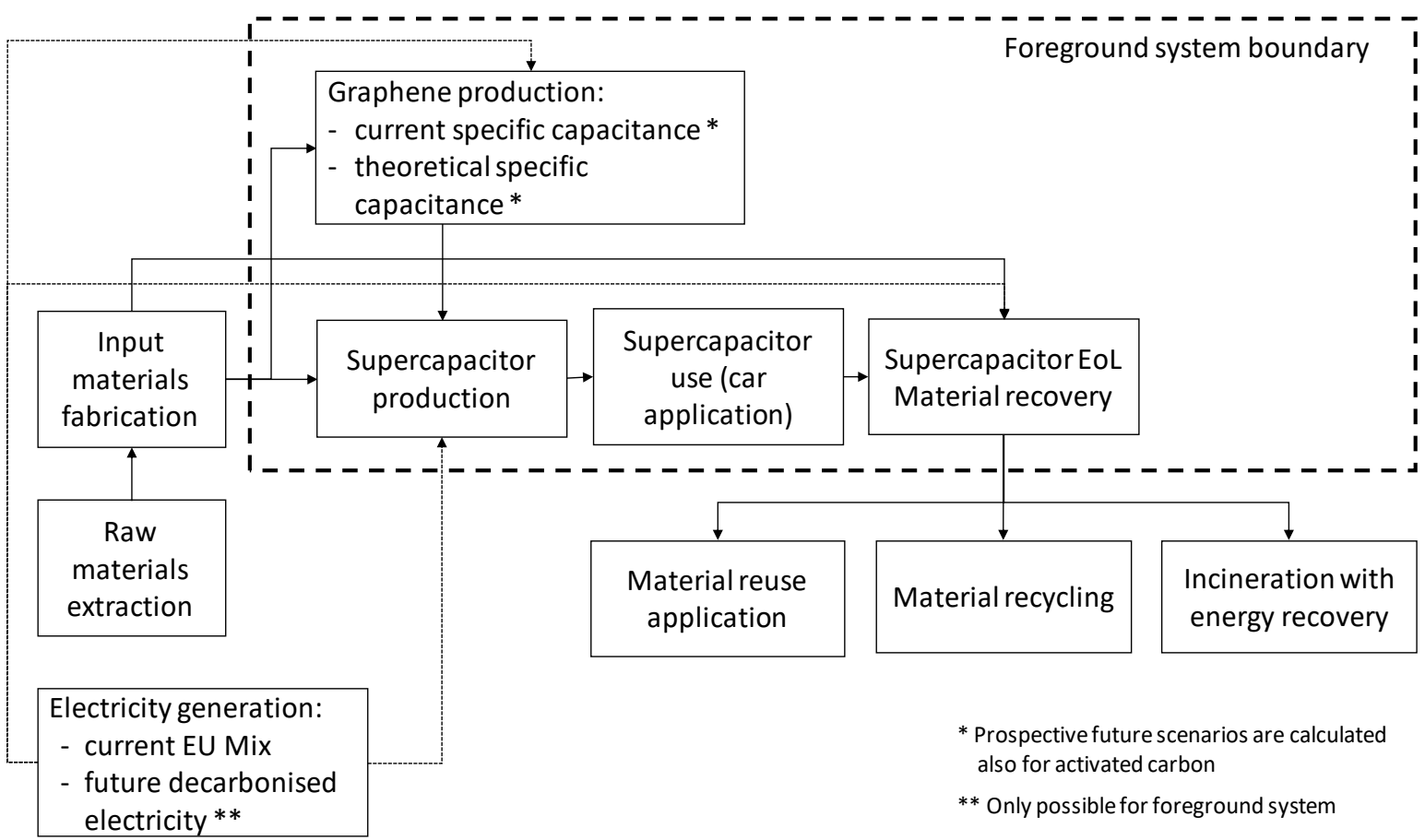

Figure 1 - LCA system boundary for the cradle to grave analysis of the graphene-based supercapacitor Foreground system: a system on which measures can be taken as result of decisions based on the study (Tillman, 2000).

Release of graphene nanomaterials and associated impacts are excluded from the LCA, but direct measurements of release in work environments during material/device production and end-of-life recycling are reported. The functional unit is defined as one supercapacitor rack of 5 supercapacitors with capacitance of 5 Farads $(F)$, as required by the case study application. This is sufficient to deliver enough energy over 20 seconds for 4 mirror movements of 5 seconds each, as validated by Centro Ricerche Fiat (2015).

The system boundary is indicated in Figure 1, and includes active materials production, supercapacitor manufacture, use in a vehicle, and recycling at end-of-life. Further details on these activities and life cycle inventory development can be found in Section 2.2. Commercial LCA software GaBi V7.0 and associated databases (Thinkstep) are utilised to develop the LCA models, employing data of most relevance to operations in Europe.

The EU electricity mix is used due to a lack of existing supply chains for graphene production and use. Transport requirements are assumed similar for both graphene and activated carbon 
pathways and can be neglected for this comparison. Infrastructure requirements, like graphene production equipment, are not included, as is common practice for LCA studies of systems where these aspects are expected to have smaller impacts than the operation of the facilities (Zhang et al., 2010).

\subsection{Life cycle inventory}

\subsubsection{Active material production and performance}

The life cycle inventory for graphene production is developed based on mass and energy balances from experimentally-informed process simulation using SuperPro designer V9.0 (Intelligen Inc.). Two graphene production routes are chosen for their relatively inexpensive production (Zhong et al., 2015) and simplicity of scalability (Lee et al., 2013), starting with graphite as a precursor:

1) Electrochemical exfoliation, which occurs in an electrolytic cell in which ions intercalate in the graphite anode weakening the Van der Waals forces between the graphite planes and leading to the detachment of graphene sheets and nanoribbons.

2) Reduced graphene oxide ( $\mathrm{rGO}$ ), produced in two principle steps of chemically oxidising graphite powder and subsequently reducing this material by thermal or chemical process to produce a porous structure of randomly oriented graphene nanoplatelets.

For both production routes, a set of process parameters are considered and experimentally evaluated to identify promising routes to graphene suitable for supercapacitor applications.

Table 1 - Summary of tested oxidations and reductions (the " $x$ " in the reductions indicates numbers from 1 to 5 as both reductions are tested with all 5 oxidations)

\begin{tabular}{lll}
\hline OXIDATION IDs & Procedure & Source \\
\hline GO1 & modified Hummers method (Fugetsu variant) & (Sun et al., 2012), \\
GO2 & Modified Hummers method (Bangal variant) & (Chen et al., 2010) \\
GO3 & Modified Hummers method (Jeong variant) & (Pham et al., 2011) \\
GO4 & Staundenmaier method & (Sheshmani and Amini, 2013) \\
GO5 & Brodie method & (Kim et al., 2010) \\
\hline REDUCTION IDs & Procedure & Source \\
\hline rGOxC & Chemical reduction with hydrazine and ammonia & (Lobato et al., 2015) \\
rGOXT & Thermal using a furnace and a precise heating profile & (Cossutta et al., 2017) \\
\hline
\end{tabular}

Specific capacitance (C) is assessed for a set of four electrochemical exfoliations and ten chemical routes. The exfoliations use sodium acetate $\left(\mathrm{CH}_{3} \mathrm{COONa}\right)$ and potassium hydroxide $(\mathrm{KOH})$ as electrolytes operating at applied potentials of 15 and $9 \mathrm{~V}$, while the chemical reactions constitute of five graphite oxidations combined with two reductions (Table 1). 
Further details on the graphene production routes considered this study and the process simulation methods employed to develop mass and energy balances for the life cycle inventory can be found in a previous publication (Cossutta et al., 2017). An example of a commercial scale graphene production is included in the SI Section S 1. All values of specific capacitance presented in this paper refer to the mass of active material (four times the corresponding F/g for a supercapacitor. Details in SI Section S 2).

The electrochemical performance of activated carbon and graphene is tested in a sandwichtype capacitor set up with two electrodes separated by a glassy fibrous paper (Whatman 934$\mathrm{AH}$, Sigma-Aldrich) and placed inside a Swagelok-cell. The graphene particles are processed as electrodes by rolling a mixture with $5 \mathrm{wt} \%$ of conductive carbon black TIMCAL Super-P and 5 wt\% PTFE (Sigma-Aldrich) into 100-160 $\mu \mathrm{m}$ thick films. Discs of $8 \mathrm{~mm}$ in diameter, carbon loading of $11-12 \mathrm{mg} / \mathrm{cm}^{2}$ and $0.91-0.98 \mathrm{~g} / \mathrm{cm}^{3}$ in density, and around $1 \mathrm{~g} / \mathrm{cm}^{3}$ for activated carbon, are punched out. The electrochemical performance is determined in $1 \mathrm{M}$ $\left(\mathrm{C}_{2} \mathrm{H}_{5}\right)_{4} \mathrm{NBF}_{4}$ /acetonitrile by galvanostatic charge-discharge cycles at different current density from 1 to $100 \mathrm{~mA} / \mathrm{cm}^{2}$. The cell voltage ranged from 0 to $2.7 \mathrm{~V}$. The electrochemical measurements were carried out in a potentiostat-galvanostat Metrohm / Autolab-Ecochimie PGSTAT30, The Netherlands. Textural characterization was accomplished by $\mathrm{N}_{2}$ adsorption at $77 \mathrm{~K}$ (Micromeritics ASAP 2010 unit, USA) and the specific surface area was determined by the BET equation. The value was confirmed by the analysis of the $\mathrm{N}_{2}$ isotherm by Quenched Solid Density Functional Theory (QSDFT). More details on this methodology can be found in publications from Domingo-García et al. (2010) and from Guardia et al. (2019).

Activated carbon manufacture is modelled using the $\mathrm{GaBi}$ synthetic activated carbon dataset as the real production process was disclosed for commercial reasons. Using activated carbon produced from renewable sources could lead to very different environmental impacts and it can be the subject for further studies. The activated carbon used for electrochemical testing was provided by Maxwell Technologies Inc (2013).

\subsubsection{Supercapacitor production}

The supercapacitor manufacturing data for a current state-of-the-art activated carbon $5 \mathrm{~F}$ supercapacitor, are provided by Maxwell Technologies Inc (2013). A similar process is assumed to be suitable for manufacturing graphene-based supercapacitors. The general assembling process starts with electrode manufacture, wherein the active material, graphene or activated carbon, is bound with PTFE to an aluminium substrate to form an electrode. Two electrodes, divided by a paper separator, are wound to form a roll. Collectors are laser welded to the roll that is then encapsulated into a cylindrical aluminium case closed at the bottom.

A rubber insulator seals the top part and a lid is laser welded on top of it to obtain an unfilled supercapacitor. The latter is then vacuum-filled with electrolyte, hermetically sealed and tested (Figure 2). The life cycle inventory (LCI) for supercapacitor manufacture is presented in SI section $\mathrm{S} 4$. 


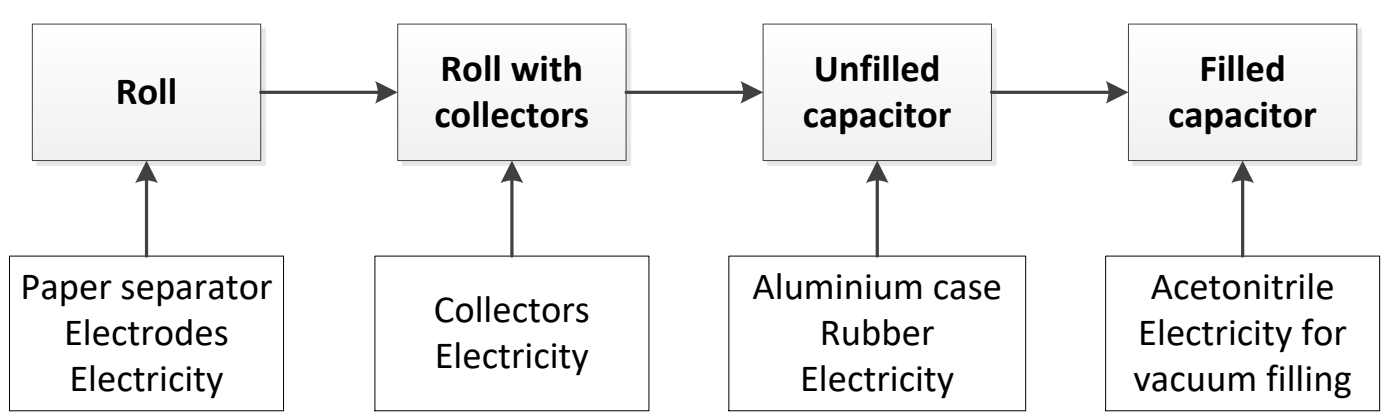

Figure 2 - Supercapacitor production main steps. Both supercapacitors are manufactured following this process; they differ in the electrode material.

The quantities of graphene and activated carbon are calculated based on the material specific capacitance (experimentally determined as described in Section 2.2.1), assuming negligible internal inefficiencies due to the commercial sensitivity of this data.

Device size is adjusted to account for differences in active material specific capacitance, which directly impacts the electrode area and device volume, while the energy use for the supercapacitor assembly is considered the same.

\subsubsection{Supercapacitor use}

The implications of supercapacitor weight on in-use fuel consumption is considered. Experimental data from Centro Ricerche Fiat (2015) indicate that for medium car - segment C, such as Volkswagen Golf, Ford Focus and others of similar size (Office for Official Publications of the European Communities, 1999) consumes around 3\% more fuel for every $100 \mathrm{~kg}$ of weight increase over an average drive cycle. This value is in line with findings for the fuel reduction values for a standard driving cycle presented by Kim et al. (2015). Using this relationship, fuel consumption attributable to carrying the supercapacitor device is calculated for the useful life of the vehicle, assumed to be $150,000 \mathrm{~km}$. Supercapacitors are anticipated to have a longer life than that of the vehicle, and do not require replacement.

\subsubsection{Material recovery at end-of-life}

Hypothetical recycling processes for graphene (Jiang and Pickering, 2017) and activated carbon supercapacitors (Jiang and Pickering, 2016) were investigated experimentally and published separately, including consideration of the properties of recovered materials and material recovery rates. The recycling process, summarised in Figure 3 , is similar for graphene and activated carbon supercapacitors. The LCA approach for the hypothetical end-of-life stages is prospective (Raugei and Winfield, 2019).

The process requires cutting the supercapacitor to extract the electrodes. The non-electrode materials are easily separated and collected manually or with a set of cyclones and filters. The electrodes undergo a pyrolysis process to decompose the binder and detach the active material from the aluminium substrate. The electrodes are placed in a nitrogen swept reactor, heated at $200{ }^{\circ} \mathrm{C}$, to distil and recover the acetonitrile. For activated carbon, this operation 
lasts $15 \mathrm{~min}$, after which the temperature is increased to $350{ }^{\circ} \mathrm{C}$ for about an hour. Subsequently, the electrode is shredded in water and the resulting suspension is filtered to separate aluminium from active material. For graphene, the electrolyte distillation lasts for $60 \mathrm{~min}$ followed by a temperature increase to $600^{\circ} \mathrm{C}$ for $5 \mathrm{~min}$ after which the binder is totally decomposed and the material falls off the electrode. This difference in the temperature profile is necessary to recover high purity materials as at $600{ }^{\circ} \mathrm{C}$ the pore structure of activated carbon collapses.

Recycling processes are assumed to recover $90 \%$ of active materials from the electrodes. Only $40 \%$ of acetonitrile is assumed to be recoverable, on the basis of the experimental work. The surface area of recovered activated carbon is measured as $95 \%$ of its original value, indicating a minor deterioration of material quality (Jiang and Pickering, 2016). Recovered graphene can directly substitute virgin graphene if used for composite applications, matching the mechanical properties of composites produced from new graphene (Jiang and Pickering, 2017).

Environmental impacts of recovered materials are modelled by substitution, meaning that material recovered displaces the production of virgin material, generating an environmental credit. The quantity displaced depends on the quality of the material recovered: $1 \mathrm{~g}$ of recovered activated carbon can displace $0.95 \mathrm{~g}$ of virgin material production due to degradation of material properties, while a 1:1 substitution of virgin graphene production is assumed as it does not exhibit a decrease in properties.

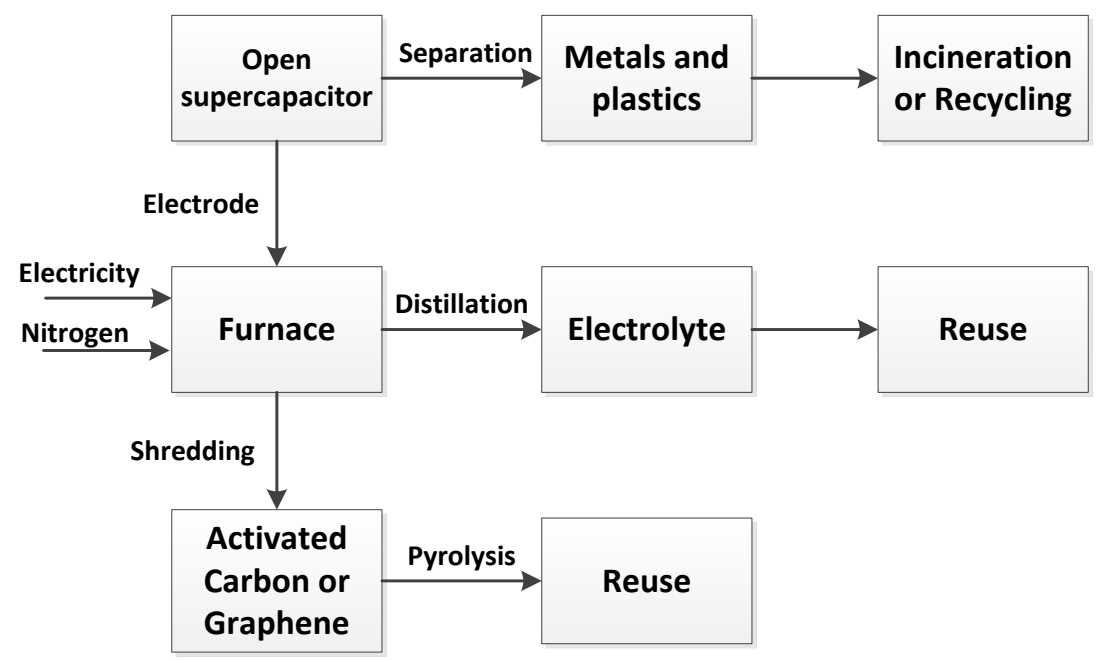

Figure 3 - Process flow for recycling graphene and activated carbon supercapacitors

The life cycle inventory for recycling processes is developed from mass and energy balances determined through process simulation. Energy requirements for shredding and filtering are excluded as measured to be negligible.

Heating energy requirements for pyrolysis are varied between the supercapacitor designs based on varying quantities of aluminium and active material that need to be heated. All other 
material recovery processes for rubber and paper incineration and aluminium recycling are modelled using generic datasets from $\mathrm{GaBi} 7$ databases. PTFE decomposition during pyrolysis and acetonitrile emission are not included as assumed to be equal for both supercapacitors. Potential impacts of process heat loss are considered following the same approach as in the graphene production model detailed in $\mathrm{SI}$ section $\mathrm{S} 1$. The $\mathrm{LCl}$ for the recycling process is presented in the SI section S 5 .

\subsection{Future scenarios}

As graphene is an emerging material, key parameters relevant to its production and use continue to be developed. A prospective life cycle approach is undertaken, wherein material specific capacitance to the theoretical maximum is considered alongside the decarbonisation of the energy mix input to the material production and recovery (Arvidsson et al., 2018). These prospective scenarios are subsequently referred to as "technological advancement" and "decarbonised". The theoretical specific capacitance used for graphene is $550 \mathrm{~F} / \mathrm{g}$ (Ke and Wang, 2016) and $200 \mathrm{~F} / \mathrm{g}$ for activated carbon, based on findings of maximum actual specific surface area and a contribution of around $0.1 \mathrm{~F} / \mathrm{m}^{2}$ in the organic electrolyte (Lobato et al., 2017). The decarbonised scenario is considered in addition to the technology advancements assuming the use of renewable electricity sources, rather than the current EU-27 generation mix, on the manufacturing and recycling of the devices. For this purpose, the Norwegian electricity mix from GaBi database is used due to its near $100 \%$ renewable mix. The evolution of the energy mix can be defined as partially prospective due to the nature of GaBi datasets, which are provided in aggregate and so it is not possible to update the source of energy inputs. Changes to the electricity mix are only possible for the modelled foreground system, that includes graphene production, supercapacitor manufacture, recycling processes, whereas the production of all input materials is based on the current energy mix.

\subsection{Interpretation}

Overall results are normalised and weighted, to enable comparison of diverse environmental and resource impacts. Normalisation is undertaken using EU-domestic-person-equivalent normalisation factors (JRC, 2016). Weighting factors are to some extent subjective and so a range of values are considered. Results are evaluated averaging three distinct weighting factor sets proposed by the JRC (Huppes et al., 2012). Normalisation and weighting indicate that global warming potential is the most important impact category (see Section 3.4). As such, results presented in the paper are focused on this metric. Results for all other impact categories are presented in the Supporting Information in the indicated sections and they include 13 mid-point categories covering an area of protection including natural environment, human health and natural resources. 


\section{Results and discussion}

\subsection{Active material and device performance}

To be suitable for supercapacitor applications, graphene must demonstrate a high specific capacitance $(\mathrm{F} / \mathrm{g})$. Both the electrochemical exfoliated graphene and the thermally reduced graphene oxides were found to achieve unacceptably low specific capacitance. The highest specific capacitance achieved for exfoliated graphene was 5 F/g, (Pullini et al., 2015), an order of magnitude less than that of other graphene materials tested. The low specific capacitance of thermally reduced graphene oxides is linked to their flat structure and lower surface area compared to chemically reduced graphenes, most likely due to a collapse of the pore structures during thermal treatment.

Figure 4 shows the structure of GO2 after thermal and chemical reduction. The thermally reduced sample results in a laminated structure made of particles the size of hundreds of micrometres. The nanoplatelets are parallelly oriented, with narrow and prolonged pores offering limited openings for electrolyte access and having a specific surface area of $379 \mathrm{~m}^{2} / \mathrm{g}$. On the contrary, the chemically reduced GO2 has a fluffy texture/morphology, an open porous structure with wide pore-size distribution accessible to electrolyte ions, and with a specific surface area of $515 \mathrm{~m}^{2} / \mathrm{g}$.
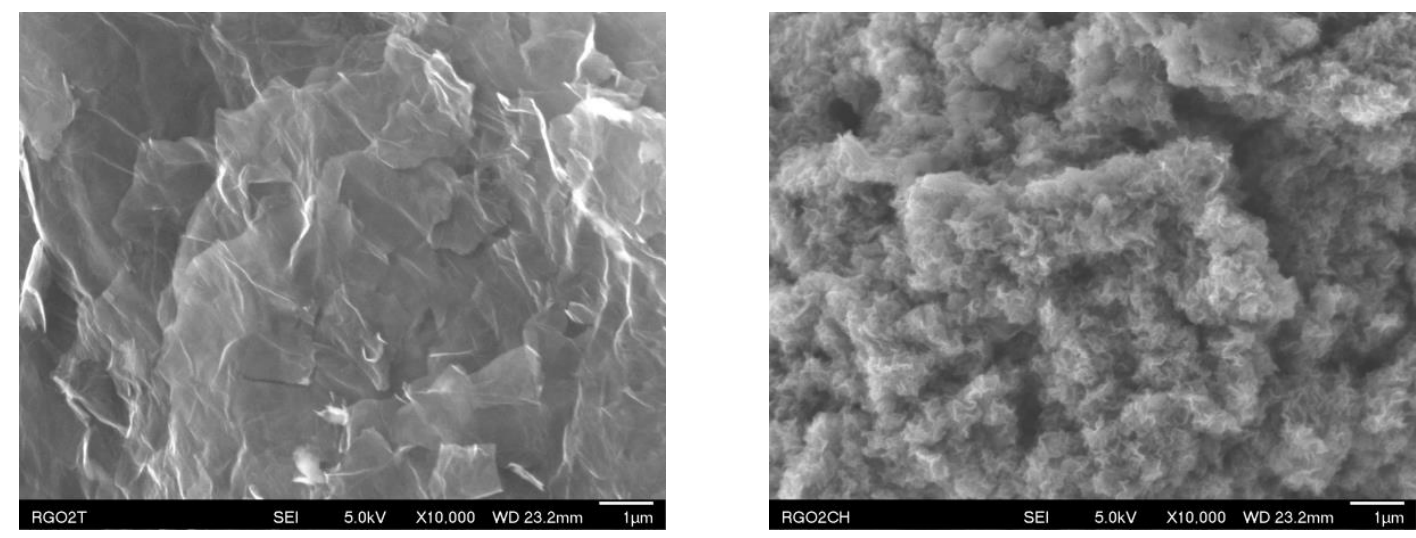

Figure 4 - SEM pictures of thermally (left) and chemically (right) reduced GO2.

The characteristics of chemically reduced graphene are limited by the incomplete clearing of oxygen from graphene oxide. Experimental results indicate that graphene output exceeds the initial graphite input ( $1 \mathrm{~g}$ vs $0.9 \mathrm{~g}$ ). The presence of oxygen negatively affects electrical conductivity. More complete reduction of graphite oxide would reduce the process mass yield and potentially improve material properties, including specific capacitance by increasing porosity, helping to achieve performance closer to theoretical values.

Of the five chemically reduced graphene oxides, the reduced graphene oxide 2 ( $\mathrm{rGO}$ ) material was found to offer the highest steady specific capacitance and so was selected for evaluation in the life cycle models and comparison with activated carbon (Figure 5). The highly varied specific capacitance among similar graphene products highlights the importance of 
including material quality assessment in LCA studies. This technical performance characteristic is essential for understanding the life cycle environmental impacts of graphenederived products.

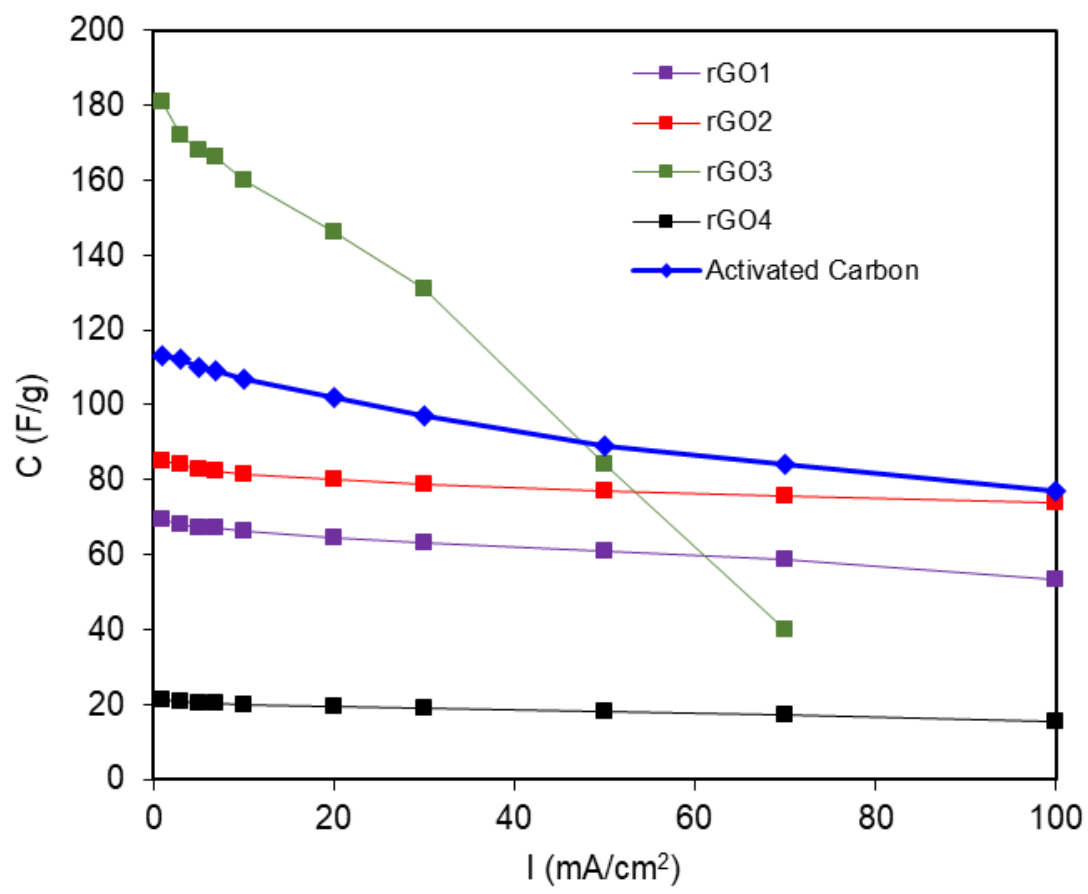

Figure 5 - Specific capacitance of different reduced graphene oxides and the activated carbon

While both graphene and activated carbon supercapacitors meet the case study requirements $(5 \mathrm{~F})$, these devices differ significantly in terms of power and energy density (Figure 6 - details in SI Section S 3).

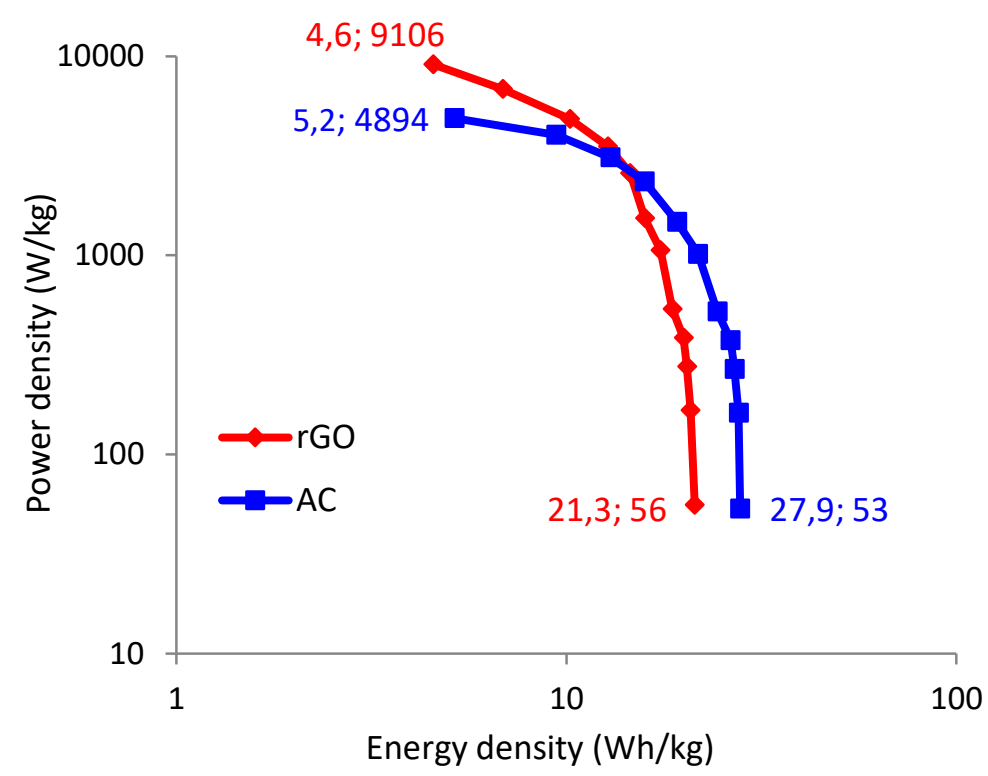

Figure 6 - Ragone plot. Comparison of energy density vs power density for both supercapacitors.

The graphene supercapacitor is capable of providing very high power densities, in excess of $9 \mathrm{~kW} / \mathrm{kg}$, approximately double that of the activated carbon device, showing the high 
potential of graphene in delivering high power in a short amount of time, as requested from supercapacitors, especially if considering the very large theoretical energy storage potential. In contrast, the activated carbon supercapacitor can achieve greater energy storage density of approximately $28 \mathrm{Wh} / \mathrm{kg}, 30 \%$ greater than that of the graphene device, but it delivers it more slowly, limiting the power output. Concerning the LCA, for other automotive applications, such differences in device performance may be material and should be appropriately considered in respective LCA studies. In the current study, both devices are capable of delivering the same functional output (20 seconds of operation).

\subsection{Supercapacitor production}

Due to differing specific capacitance, the activated carbon and graphene-based supercapacitors differ in size and active material requirements. As a result, the activated carbon supercapacitor is slightly smaller than the graphene-based device. The mass of active material needed for 5 supercapacitors is $1.1 \mathrm{~g}$ and $1.35 \mathrm{~g}$ for activated carbon and graphene allowing for $10 \%$ material loss during manufacture (SI Table 2 ).

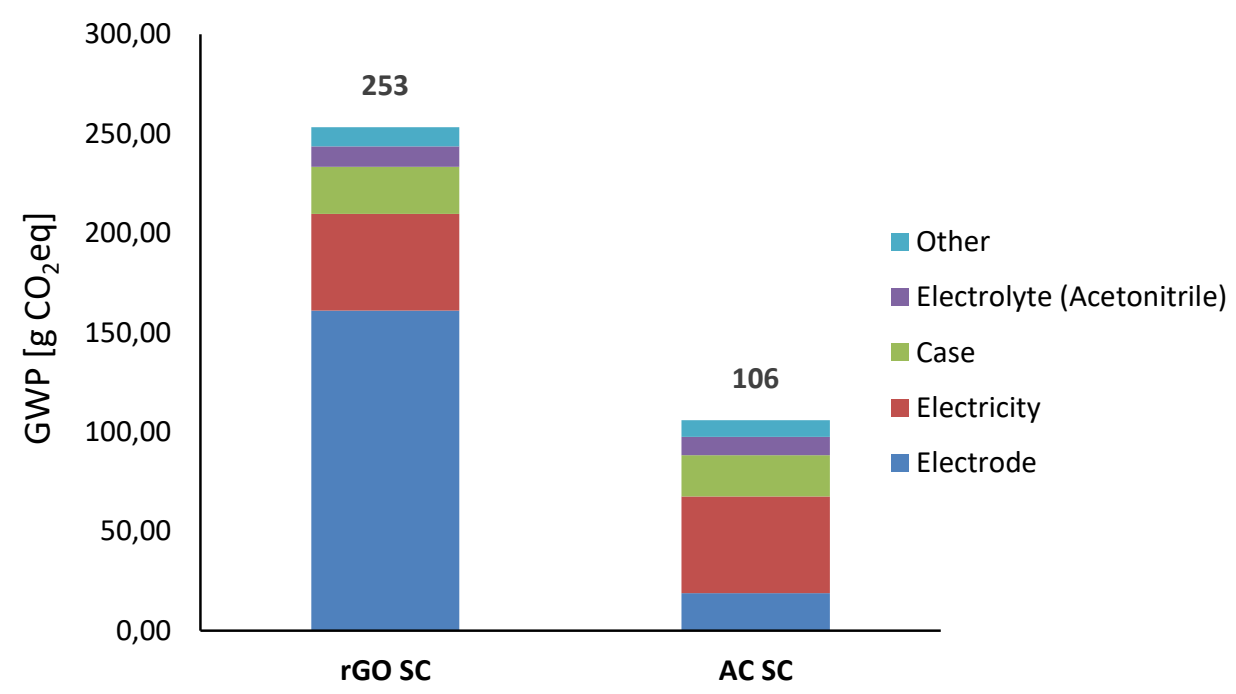

Figure 7 - Production phase - GWP comparison between a graphene-based and activated carbon-based rack of 5 supercapacitors having a capacitance of $5 \mathrm{~F}$ each.

The global warming potential (GWP) associated with manufacturing the graphene-based supercapacitor is approximately 2.5 times that of the activated carbon-based device (Figure 7). The key contributor is the production of graphene - not only is the active material requirement greater for the graphene supercapacitor, but the production of this material is also more greenhouse gas-intensive than activated carbon ( $\sim 0 \mathrm{gCO}_{2} \mathrm{eq}$./g vs $5 \mathrm{gCO}_{2} \mathrm{eq}$./g). The larger size, and correspondingly greater material requirements for the device casing, electrolyte, and other materials, has a minor effect on the results. The activated carbon-based device is the least impacting in all analysed impact categories, with the exception of ozone depletion, for which impacts are similar with a small advantage for the graphene based device. Results for all impact categories for supercapacitor production are presented in SI Section S4. 


\subsection{Supercapacitor End of Life}

Recycling of both graphene and activated carbon supercapacitors delivers a net reduction in GHG emissions. This due to the emissions savings associated with the provision of recovered materials and corresponding displacement of primary production exceeding the emissions of the recycling processes (Figure 8 ). Graphene recovery provides a substantial reduction in GWP, due to the high impacts associated with the primary production of this material. Aluminium recovery provides a similar benefit to both device designs. The largest contributor to these burdens is the nitrogen used in the pyrolysis process, but this could potentially be lessened by reducing the nitrogen input rate or recovering adequately pure nitrogen for reuse. For all impact categories, supercapacitor recycling delivers a net reduction in impact.

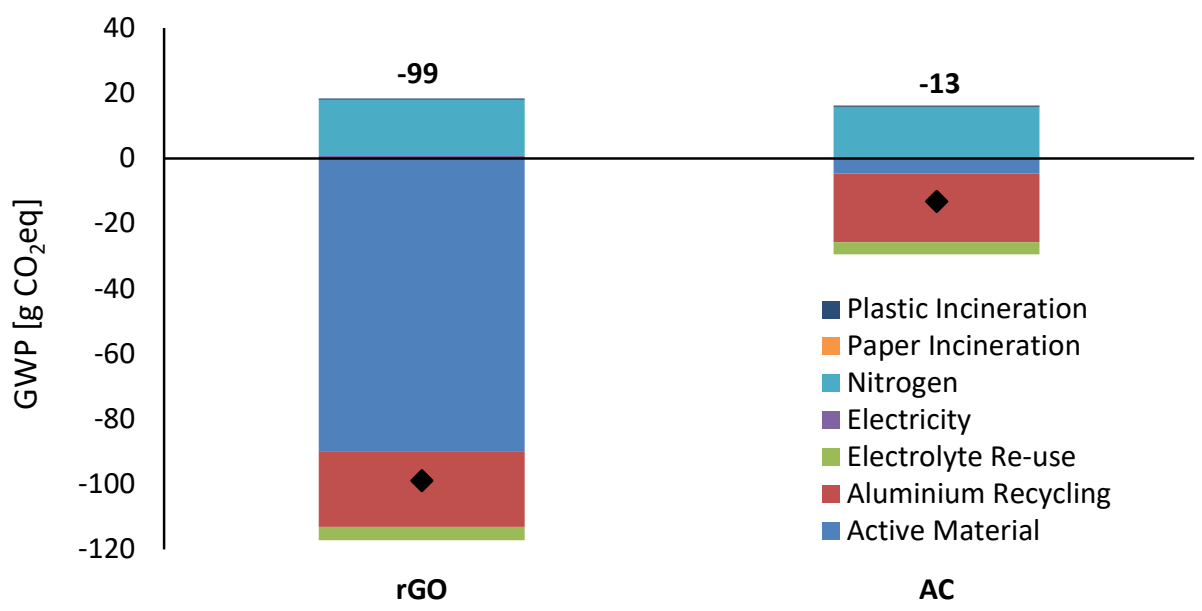

Figure 8 - End of Life - GWP comparison between a graphene based and activated carbon-based rack of 5 supercapacitors having a capacitance of $5 \mathrm{~F}$ each

The benefits of graphene device recycling are generally greater than those of activated carbon device recycling. The sole exception is ozone depletion, as avoiding activated carbon production has a slight advantage for this metric. The full EoL phase results, including all impact categories, is presented in the Supporting Information (Section S 5).

\subsection{Full life cycle results}

Graphene-based supercapacitors - with current material performance and energy mix represent a greater environmental burden than conventional activated carbon-based devices (Figure 9). A key factor in the poor performance of the graphene supercapacitor is the high greenhouse gas-intensity of primary graphene production, which dominates the production emissions as explained in Section 3.2. The inferior specific capacitance of graphene tested in the present study, when compared with activated carbon, results in a larger and heavier device that requires more active material and greater material inputs, incurring greater usephase impacts due to mass-induced fuel consumption.

Recycling is critical for minimising the greenhouse gas emissions of the graphene supercapacitor. The reuse of recovered materials avoids significant impacts of primary material production, primarily graphene, reducing the overall impact attributable to the 
graphene device. If recycling of the supercapacitor devices is not available, the net GWP of the graphene-based device would increase by approximately $50 \%$, and total impact would be double that of an activated carbon device with no recycling. Ensuring the availability of recycling infrastructure, and the market for secondary graphene, should be considered a priority when developing products using this emerging material.

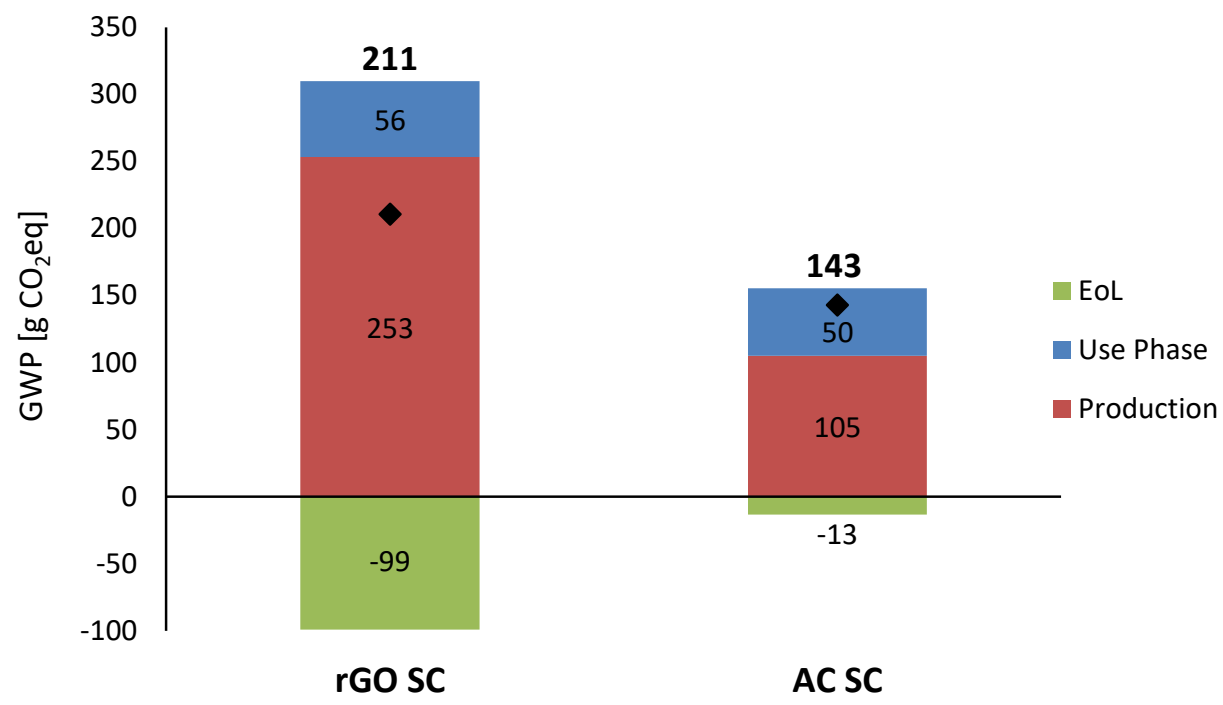

Figure 9 - cradle to grave LCA of both supercapacitors.

The squared symbol marks the total value when summing all three phases

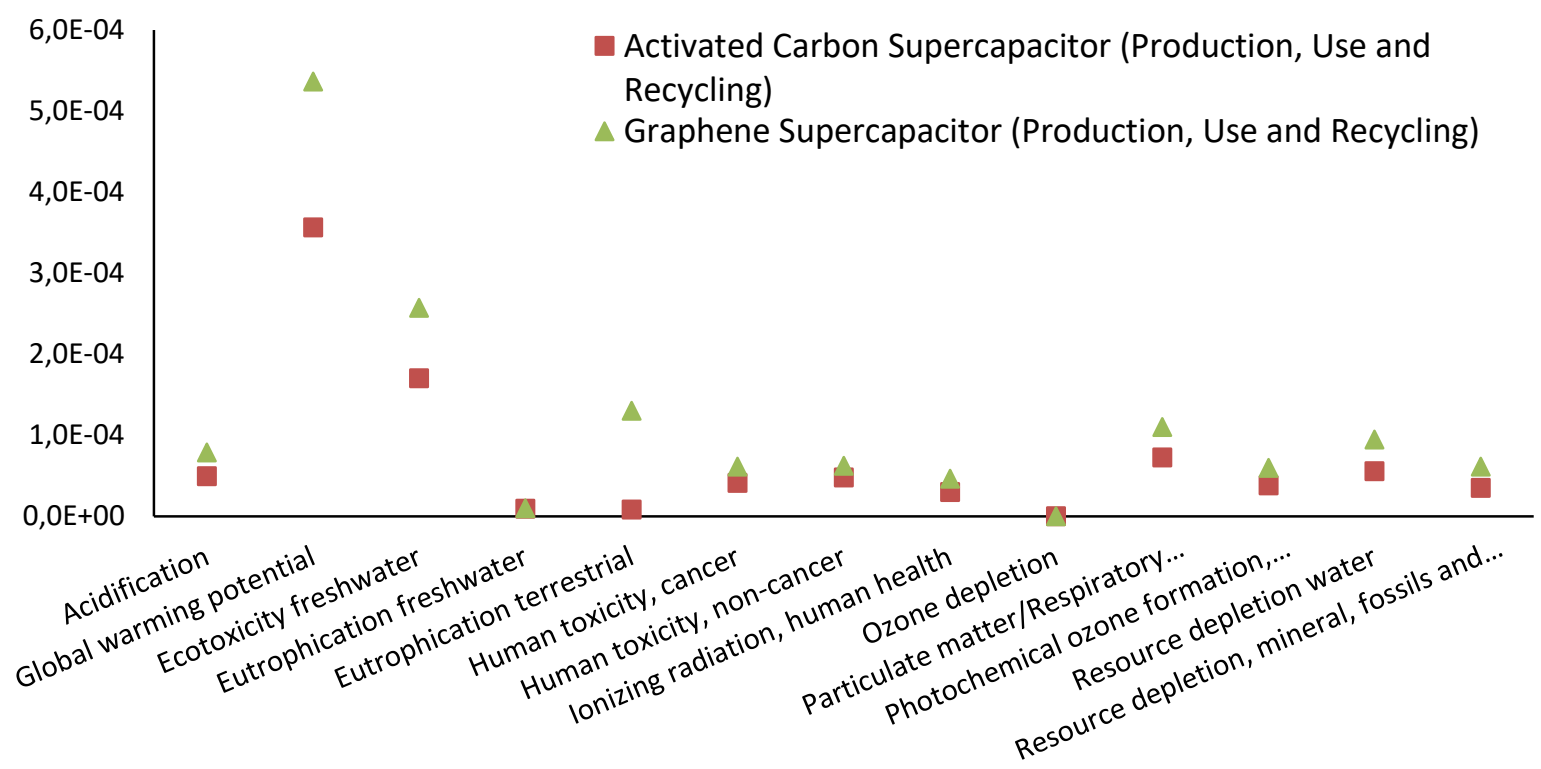

Figure 10 - Normalised and weighted results for all impact categories

The relative GWP impacts of graphene and activated carbon supercapacitors is mirrored in all the other impact categories (Supporting Information, Section S6). The normalised and weighted results are in relation to the average European emissions per person per year and demonstrate that, for the weighting factors considered, the global warming potential is the 
most problematic impact category, followed by the fresh water ecotoxicity. Weighting is by nature a subjective exercise, and as such, these relative results should be considered carefully and within the context of the assumptions used for the weighting analysis.

Overall, the graphene supercapacitor is the most impacting in all categories, ranging from a $27 \%$ higher human toxicity (carcinogenic), to $213 \%$ greater ozone depletion relative to activated carbon supercapacitor.

As mentioned in Section 2.1, the impacts of nanomaterial emission are excluded from this study due to a lack of understanding of nanoparticle emission rates and exposure risks. The risk of nanomaterial emissions in the work environment were investigated (MacCalman et al., 2015), finding no detectable emission under standard control measures and good laboratory practices. This finding does not account for the risk of nanomaterial release during other activities and life cycle stages, including exposure routes outside the work environment, and is an important research topic to better understand and minimise graphene toxicological hazards.

\subsection{Future scenarios}

GHG emissions associated with supercapacitor manufacture and use can be substantially reduced through production technology improvements and the ongoing decarbonisation of process electricity sources. Improvements in graphene specific capacitance compared to values reported in this study have been achieved in other literature, where values of $\sim 100$ F/g (Ambrosi and Pumera, 2016) to more than 200 F/g (Gong et al., 2017) and (Alhabeb et al., 2017) have been reached. Further improvements in material properties will realise and move the current values of specific capacitance closer to the theoretical maximum of $550 \mathrm{~F} / \mathrm{g}$. Achieving this theoretical performance would greatly reduce environmental impacts associated with the graphene-based supercapacitor (Figure 11). The quantity of graphene required to achieve the same device capacitance would be reduced by nearly $75 \%$ compared to the current material performance. Overall, life cycle GWP would be reduced by approximately $60 \%$, with substantial reductions in impact associated with supercapacitor production $(>80 \%)$ and use phase $(65 \%)$, due to the much smaller device size. If activated carbon is able to achieve its theoretical specific capacitance, impacts would be reduced, although less substantially ( $30 \%$ reduction in impacts). Overall, an "ideal" graphene supercapacitor with the theoretical maximum active material specific capacitance would achieve a slightly lower GWP than an "ideal" activated carbon-based device. An improved graphene production process that is more energy- and material-efficient would further decrease the environmental impacts of supercapacitors based on this material.

Increased use of renewable electricity further reduces the GWP impact of both graphene and activated carbon supercapacitors (Figure 11). Use of renewable electricity provides a greater relative benefit for the graphene-based supercapacitor, as graphene production requires significant electricity inputs, whereas the main energy input to activated carbon production 
is natural gas (Hjaila et al., 2013). GWP associated with device manufacturing inputs is also reduced, as electricity is consumed in the assembly processes.

The influence of enhanced material performance and electricity decarbonisation on other impact categories is shown in the Supporting Information (Section S7) and results mirror those for GWP. The sensitivity of results to the electricity source indicates that the location of operations, with its generation mix of electricity supplied to the production and recycling processes, has a substantial influence on the total life cycle environmental impacts of graphene-based supercapacitors and, by extension, other graphene-based devices. Opportunities for minimising environmental impact could be gained by informing production location decisions with data on regional energy and material footprints, considering worldwide (Giljum et al., 2015) or European (Steen-Olsen et al., 2012) perspectives.

The prospective methodology adopted in this study is in line with the novel recommendations for emerging technologies evaluation from Arvidsson et al. (2018), which suggest undertaking scenario analysis to consider both technology development and background systems evolution to inform long-term decision making. A background system is system influenced by decision taken in the foreground system, but not under direct control (Tillman, 2000).

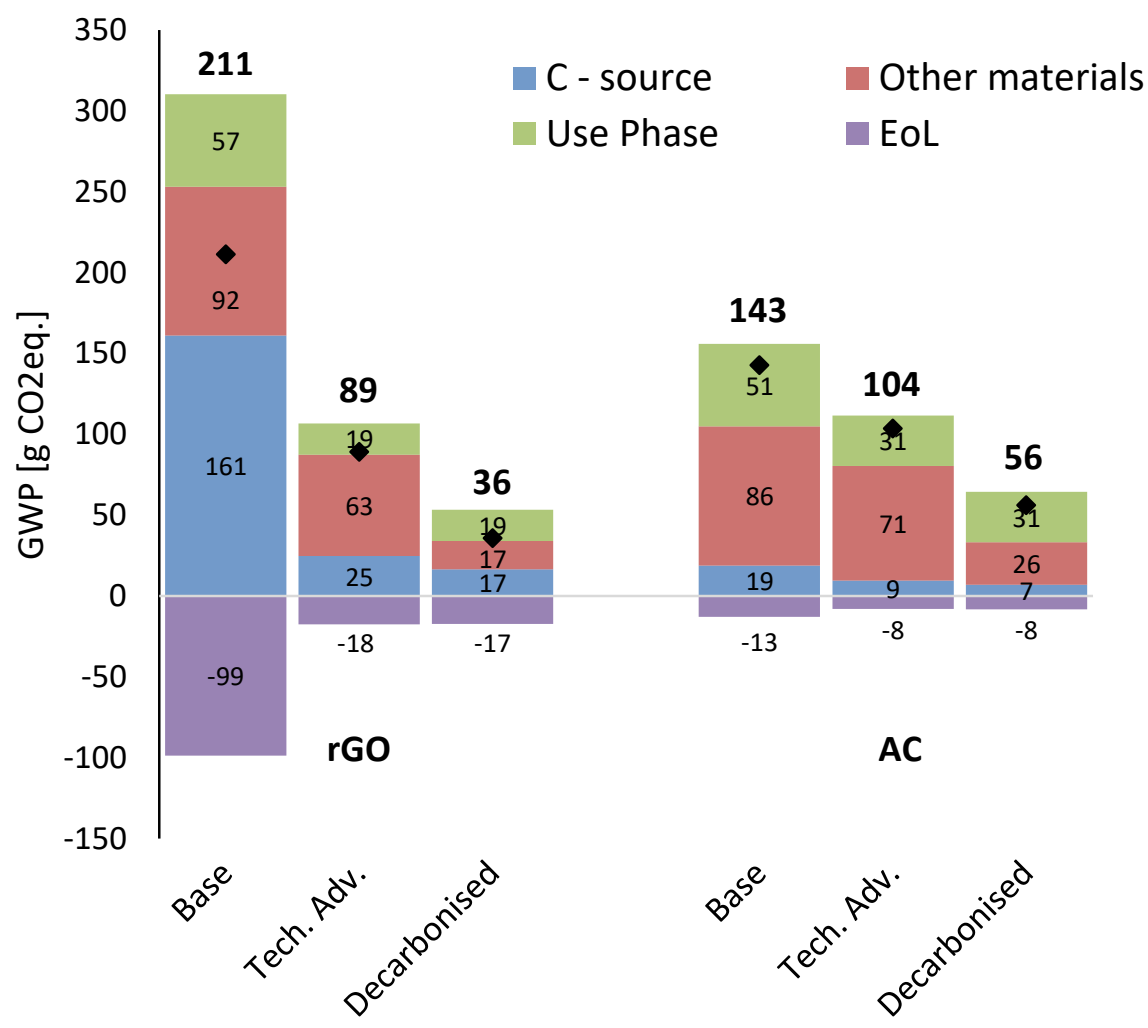

Figure 11 - Global warming potential scenario comparison: if properties of the material are enhanced, sulphuric acid reused, the graphene has the potential to become the least impacting technology

Results presented here are in line with previous assessments of graphene, where decarbonisation of the electricity input was similarly identified to reduce GWP by an order of magnitude relative to the current EU electricity mix (Arvidsson and Molander, 2017). 


\section{Conclusions}

Graphene is a promising material, yet little is known about its environmental impacts. This study provides a better understanding of key issues related to the environmental impacts of a case study graphene-based device and evaluates a potential recycling route that would enable the recovery of high-quality graphene for reuse. Achieving significant technical performance improvements with graphene over current materials, for a specific application, is critical to delivering overall reductions in environmental impacts. This factor has not been considered in detail by previous studies, risking inaccurate estimation of the overall implications of graphene production and use in specific applications. A key knowledge gap relates to the development of emission inventory data and impact assessment methodologies related to nanomaterial release and exposure. Such impacts could significantly alter the findings of the present study and previous analyses of nanomaterial production and use. Overall, to realise the environmental opportunities of this emerging material, it is essential that 1) superior technical performance is achieved relative to conventional and/or competitor materials; 2 ) that the upstream supply chain is evaluated to identify opportunities to utilise lower-impact inputs; 3) that graphene production is made more efficient reducing input requirements; and 4) that recycling processes and infrastructure are developed and deployed to ensure the recoverability of graphene at end-of-life. These findings are of relevance to all graphene applications, including in catalysis, membranes, energy storage, electricity generation, and materials applications.

\section{Conflicts of interest}

There are no conflicts of interest to declare

\section{Acknowledgements}

This research has received funding from the European Commission's Seventh Framework Programme (FP7/2007-2013) under grant agreement no. 266391. 


\section{References}

Alhabeb, M., Beidaghi, M., Van Aken, K. L., Dyatkin, B., and Gogotsi, Y., 2017. High-density freestanding graphene/carbide-derived carbon film electrodes for electrochemical capacitors. Carbon 118, 642-649.

Alwarappan, S., Erdem, A., Liu, C., and Li, C.-Z., 2009. Probing the Electrochemical Properties of Graphene Nanosheets for Biosensing Applications. J. Phys. Chem. C 113, 8853-8857.

Ambrosi, A., and Pumera, M., 2016. Electrochemically Exfoliated Graphene and Graphene Oxide for Energy Storage and Electrochemistry Applications. Chem. - A Eur. J. 22, 153-159.

Arvidsson, R., Kushnir, D., Molander, S., and Sandén, B. A., 2016. Energy and resource use assessment of graphene as a substitute for indium tin oxide in transparent electrodes. J. Clean. Prod. 132, 289-297.

Arvidsson, R., Kushnir, D., Sandén, B. A., and Molander, S., 2014. Prospective Life Cycle Assessment of Graphene Production by Ultrasonication and Chemical Reduction. Environ. Sci. Technol. 48, 4529-4536.

Arvidsson, R., and Molander, S., 2017. Prospective Life Cycle Assessment of Epitaxial Graphene Production at Different Manufacturing Scales and Maturity. J. Ind. Ecol. 21, 1153-1164.

Arvidsson, R., Tillman, A.-M., Sandén, B. A., Janssen, M., Nordelöf, A., Kushnir, D., and Molander, S., 2018. Environmental Assessment of Emerging Technologies: Recommendations for Prospective LCA. J. Ind. Ecol. 22, 1286-1294.

Balandin, A. A., Ghosh, S., Bao, W., Calizo, I., Teweldebrhan, D., Miao, F., and Lau, C. N., 2008. Superior Thermal Conductivity of Single-Layer Graphene. Nano Lett. 8, 902-907.

Bauer, C., Buchgeister, J., Hischier, R., Poganietz, W. R., Schebek, L., and Warsen, J., 2008. Towards a framework for life cycle thinking in the assessment of nanotechnology. J. Clean. Prod. 16, 910926.

Centro Ricerche Fiat. 2015. Website: https://www.crf.it/EN.

Chen, W., Yan, L., and Bangal, P. R., 2010. Preparation of graphene by the rapid and mild thermal reduction of graphene oxide induced by microwaves. Carbon 48, 1146-1152.

Cossutta, M., McKechnie, J., and Pickering, S. J., 2017. A comparative LCA of different graphene production routes. Green Chem. 19, 5874-5884.

Domingo-García, M., Fernández, J. A., Almazán-Almazán, M. C., López-Garzón, F. J., Stoeckli, F., and Centeno, T. A., 2010. Poly(ethylene terephthalate)-based carbons as electrode material in supercapacitors. Journal of Power Sources 195, 3810-3813.

Gilbertson, L. M., Wender, B. A., Zimmerman, J. B., and Eckelman, M. J., 2015. Coordinating modeling and experimental research of engineered nanomaterials to improve life cycle assessment studies. Environ. Sci. Nano 2, 669-682.

Giljum, S., Bruckner, M., and Martinez, A., 2015. Material Footprint Assessment in a Global InputOutput Framework. J. Ind. Ecol. 19, 792-804.

Gong, Y., Ping, Y., Li, D., Luo, C., Ruan, X., Fu, Q., and Pan, C., 2017. Preparation of high-quality graphene via electrochemical exfoliation \& spark plasma sintering and its applications. Appl. Surf. Sci. 397, 213-219.

Griffiths, O. G., O'Byrne, J. P., Torrente-Murciano, L., Jones, M. D., Mattia, D., and McManus, M. C., 2013. Identifying the largest environmental life cycle impacts during carbon nanotube synthesis via chemical vapour deposition. J. Clean. Prod. 42, 180-189.

Guardia, L., Suárez, L., Querejeta, N., Vretenár, V., Kotrusz, P., Skákalová, V., and Centeno, T. A., 2019. Biomass waste-carbon/reduced graphene oxide composite electrodes for enhanced supercapacitors. Electrochim. Acta 298, 910-917. 
Guarino, S., Ucciardello, N., Venettacci, S., and Genna, S., 2017. Life cycle assessment of a new graphene-based electrodeposition process on copper components. J. Clean. Prod. 165, 520529.

Healy, M. L., Dahlben, L. J., and Isaacs, J. A., 2008. Environmental Assessment of Single-Walled Carbon Nanotube Processes. J. Ind. Ecol. 12, 376-393.

Hjaila, K., Baccar, R., Sarrà, M., Gasol, C. M., and Blánquez, P., 2013. Environmental impact associated with activated carbon preparation from olive-waste cake via life cycle assessment. J. Environ. Manage. 130, 242-247.

Huppes, G., van Oers, L., Pretato, U., and Pennington, D., 2012. Weighting environmental effects: Analytic survey with operational evaluation methods and a meta-method. Int J Life Cycle Assess 17, 876-891.

Intelligen Inc., SuperPro Designer. [cited 2019 03]; Available from: http://www.intelligen.com/superpro overview.html.

Jiang, G., and Pickering, S. J., 2016. Recycling supercapacitors based on shredding and mild thermal treatment. Waste Manag. 48, 465-470.

Jiang, G., and Pickering, S. J., 2017. Recycling Graphene from Supercapacitor Electrodes as Reinforcing Filler for Epoxy Resins. Waste Biomass Valorization.

JRC. 2010. ILCD handbook - Recommendations for Life Cycle Impact Assessment in the European context. Institute for environment and sustainability European Commission Joint Research Centre, Luxembourg: Publications Office of the European Union.

JRC. 2016. Product Environmental Footprint Pilot Guidance - Guidance for the implementation of the EU Product Environmental Footprint (PEF) during the Environmental Footprint (EF) pilot phase. Institute for environment and sustainability European Commission Joint Research Centre. [cited 2018 02]; Available from: http://ec.europa.eu/environment/eussd/smgp/pdf/Guidance products.pdf.

$\mathrm{Ke}, \mathrm{Q}$., and Wang, J., 2016. Graphene-based materials for supercapacitor electrodes - A review. J. Mater. 2, 37-54.

Khalid, P., Hussain, M., Suman, V., and Arun, A., 2016. Toxicology of carbon nanotubes-a review. Int. J. Appl. Eng. Res. 11, 148-157.

Khanam, P. N., Popelka, A., Alejji, M., and AlMaadeed, M., 2017. Biotechnological Production Process and Life Cycle Assessment of Graphene. J. Nanomater. 2017.

Kim, H., Abdala, A. A., and Macosko, C. W., 2010. Graphene/Polymer Nanocomposites. Macromolecules 43, 6515-6530.

Kim, H. C., Wallington, T. J., Sullivan, J. L., and Keoleian, G. A., 2015. Life Cycle Assessment of Vehicle Lightweighting: Novel Mathematical Methods to Estimate Use-Phase Fuel Consumption. Environ. Sci. Technol. 49, 10209-10216.

Lalwani, G., D'Agati, M., Khan, A. M., and Sitharaman, B., 2016. Toxicology of graphene-based nanomaterials. Adv. Drug Deliv. Rev. 105, 109-144.

Landvik, N. E., Skaug, V., Mohr, B., Verbeek, J., and Zienolddiny, S., 2018. Criteria for grouping of manufactured nanomaterials to facilitate hazard and risk assessment, a systematic review of expert opinions. Regul. Toxicol. Pharmacol. 95, 270-279.

Lee, C., Wei, X., Kysar, J. W., and Hone, J., 2008. Measurement of the Elastic Properties and Intrinsic Strength of Monolayer Graphene. Science 321, 385-388.

Lee, S., Eom, S. H., Chung, J. S., and Hur, S. H., 2013. Large-scale production of high-quality reduced graphene oxide. Chem. Eng. J. 233, 297-304.

Lekakou, C., Sorniotti, A., Lei, C., Markoulidis, F., Wilson, P., Santucci, A., Tennison, S., Amini, N., Trapalis, C., Carotenuto, G., Khalil, S., Martorana, B., Cannavaro, I., Gosso, M., Perry, J., Hoy, C., Weil, M., Dura, H., and Viotto, F., 2015. AUTOSUPERCAP: Development of High Energy and High Power Density Supercapacitor Cells. Pages 33-43 in E. Briec and B. Müller, editors. Electric Vehicle Batteries: Moving from Research towards Innovation. Springer International Publishing. 
Lobato, B., Suárez, L., Guardia, L., and Centeno, T. A., 2017. Capacitance and surface of carbons in supercapacitors. Carbon 122, 434-445.

Lobato, B., Vretenár, V., Kotrusz, P., Hulman, M., and Centeno, T. A., 2015. Reduced graphite oxide in supercapacitor electrodes. J. Colloid Interface Sci. 446, 203-207.

Long, W.-J., Zheng, D., Duan, H.-b., Han, N., and Xing, F., 2018. Performance enhancement and environmental impact of cement composites containing graphene oxide with recycled fine aggregates. J. Clean. Prod. 194, 193-202.

MacCalman, L., Billett, S., Gillian, C., Craig Poland, Julia Varet, Dominique Balharry, and Hankin, S., 2015. Institute of Occupational Medicine (I.O.M.) - Risk Assessment - Electrograph D7.6.

Maxwell Technologies Inc., 2013. Website: http://www.maxwell.com.

Office for Official Publications of the European Communities. 1999. Regulation (EEC) No 4064/89 Merger Procedure. [cited 201826 Nov]; Available from: http://ec.europa.eu/competition/mergers/cases/decisions/m1406 en.pdf.

Pham, T. A., Kim, J. S., Kim, J. S., and Jeong, Y. T., 2011. One-step reduction of graphene oxide with Iglutathione. Colloids Surfaces A Physicochem. Eng. Asp. 384, 543-548.

Pourzahedi, L., Zhai, P., Isaacs, J. A., and Eckelman, M. J., 2017. Life cycle energy benefits of carbon nanotubes for electromagnetic interference (EMI) shielding applications. J. Clean. Prod. 142, 1971-1978.

Pullini, D., Siong, V., Tamvakos, D., Lobato Ortega, B., Sgroi, M. F., Veca, A., Glanz, C., Kolaric, I., and Pruna, A., 2015. Enhancing the capacitance and active surface utilization of supercapacitor electrode by graphene nanoplatelets. Compos. Sci. Technol. 112, 16-21.

Raugei, M., and Winfield, P., 2019. Prospective LCA of the production and EoL recycling of a novel type of Li-ion battery for electric vehicles. J. Clean. Prod. 213, 926-932.

Salieri, B., Turner, D. A., Nowack, B., and Hischier, R., 2018. Life cycle assessment of manufactured nanomaterials: Where are we? Nanolmpact 10, 108-120.

Sheshmani, S., and Amini, R., 2013. Preparation and characterization of some graphene based nanocomposite materials. Carbohydr. Polym. 95, 348-359.

Steen-Olsen, K., Weinzettel, J., Cranston, G., Ercin, A. E., and Hertwich, E. G., 2012. Carbon, Land, and Water Footprint Accounts for the European Union: Consumption, Production, and Displacements through International Trade. Environ. Sci. Technol. 46, 10883-10891.

Sun, L., Yu, H., and Fugetsu, B., 2012. Graphene oxide adsorption enhanced by in situ reduction with sodium hydrosulfite to remove acridine orange from aqueous solution. J. Hazard. Mater. 203204, 101-110.

Sun, T. Y., Bornhöft, N. A., Hungerbühler, K., and Nowack, B., 2016. Dynamic Probabilistic Modeling of Environmental Emissions of Engineered Nanomaterials. Environ. Sci. Technol. 50, 4701-4711.

Thinkstep. 2016. GaBi. [cited 201626 Nov]; Available from: https://thinkstep.com/software/gabisoftware.

Tillman, A.-M., 2000. Significance of decision-making for LCA methodology. Environmental Impact Assessment Review 20, 113-123.

Trompeta, A. F., Koklioti, M. A., Perivoliotis, D. K., Lynch, I., and Charitidis, C. A., 2016. Towards a holistic environmental impact assessment of carbon nanotube growth through chemical vapour deposition. J. Clean. Prod. 129, 384-394.

Upadhyayula, V. K. K., Meyer, D. E., Curran, M. A., and Gonzalez, M. A., 2012. Life cycle assessment as a tool to enhance the environmental performance of carbon nanotube products: a review. J. Clean. Prod. 26, 37-47.

Upadhyayula, V. K. K., Meyer, D. E., Gadhamshetty, V., and Koratkar, N., 2017. Screening-Level Life Cycle Assessment of Graphene-Poly(ether imide) Coatings Protecting Unalloyed Steel from Severe Atmospheric Corrosion. ACS Sustain. Chem. Eng. 5, 2656-2667.

Weil, M., Dura, H., Shimon, B., Baumann, M., Zimmermann, B., Ziemann, S., Lei, C., Markoulidis, F., Lekakou, T., and Decker, M., 2012. Ecological assessment of nano-enabled supercapacitors for automotive applications. Page 012013 in IOP Conf. Ser. Mater. Sci. Eng. IOP Publishing. 
Zhang, Y., McKechnie, J., Cormier, D., Lyng, R., Mabee, W., Ogino, A., and MacLean, H. L., 2010. Life Cycle Emissions and Cost of Producing Electricity from Coal, Natural Gas, and Wood Pellets in Ontario, Canada. Environ. Sci. Technol. 44, 538-544.

Zhong, Y. L., Tian, Z., Simon, G. P., and Li, D., 2015. Scalable production of graphene via wet chemistry: progress and challenges. Mater. Today 18, 73-78.

Zhu, Y., Murali, S., Cai, W., Li, X., Suk, J. W., Potts, J. R., and Ruoff, R. S., 2010. Graphene and Graphene Oxide: Synthesis, Properties, and Applications. Adv. Mater. 22, 3906-3924.

Zimmermann, B. M., Dura, H., Baumann, M. J., and Weil, M. R., 2015. Prospective time-resolved LCA of fully electric supercap vehicles in Germany. Integr. Environ. Assess. Manag. 11, 425-434. 